\title{
A Cross-Sectional Study on the Hygienic Practices among Medical and Nursing Students at the University of Hail, Kingdom of Saudi Arabia
}

Mohd. Saleem ${ }^{1}$, Fahaad Alenazi ${ }^{2}$, Soha Abdallah Moursi ${ }^{3}$, Talal Banan Alanazi ${ }^{4}$, Arkan Hamed Alshammari ${ }^{4}$, Turki Saad Aljuhani ${ }^{4}$, Moath Ibrahim Ayad Alzapni ${ }^{4}$, Azharuddin Sajid Syed Khaja ${ }^{5 *}$

${ }^{1}$ Ph.D., Department of Pathology, College of Medicine, University of Hail, Hail, Kingdom of Saudi Arabia

${ }^{2}$ Ph.D., Vice Dean of Quality and Development, Department of pharmacology, College of Medicine, University of Hail, Hail, Kingdom of Saudi Arabia

${ }^{3}$ Ph.D., Department of Pathology, College of Medicine, University of Hail, Hail, Kingdom of Saudi Arabia

${ }^{4}$ Medical Student, College of Medicine, University of Hail, Hail, Kingdom of Saudi Arabia

${ }^{5}$ Ph.D., Department of Pathology, College of Medicine, University of Hail, Hail, Kingdom of Saudi Arabia

DOI: $10.36348 /$ sjpm.2020.v05i08.002 $\quad$ | Received: 30.07 .2020 | Accepted: 08.08.2020 | Published: 14.08 .2020

*Corresponding author: Dr. Azharuddin Sajid Syed Khaja

\section{Abstract}

General and hand hygienic practices are cost-effective methods to prevent the transmission of nosocomial infections. Hand hygiene practices are faulty in most healthcare settings. This study is designed to assess the general and hand hygiene practices among medical and nursing students of the University of Hail in the Kingdom of Saudi Arabia. This is a cross-sectional study conducted among medical and nursing students. A detailed questionnaire was prepared and piloted before the final interview. The participation of students was voluntary and the questionnaires were kept anonymous. The majority of the medical and nursing students, who participated in this study, were males (88\%), with $94 \%$ in the college of medicine and $82 \%$ in the college of nursing. The majority of both medical and nursing students had good hygienic and good hand washing practices. Hand washing practices were almost similar ( $>0.05)$ in both male and female students. This study showed a higher percentage of general and handwashing hygienic practices among medical and nursing students. However, multifaceted and dedicated efforts must be undertaken to rectify this practice from early on.

Keywords: Hygienic practices, Handwashing practices, Medical students, Nursing Students.

Copyright @ 2020: This is an open-access article distributed under the terms of the Creative Commons Attribution license which permits unrestricted use, distribution, and reproduction in any medium for non-commercial use (NonCommercial, or CC-BY-NC) provided the original author and sources are credited.

\section{INTRODUCTION}

Healthcare-associated infections (HCAIs) are a cause of severe concern across the globe in primary and advanced healthcare settings. These infections not only pose a serious threat to the patients' lives but also add an extra financial burden to the governments and the healthcare service providers [1, 2]. Multidrug resistance pathogens, such as methicillin-resistant Staphylococcus aureus (MRSA) further make these HCAIs more dangerous, which are sometimes very difficult to treat [3]. These healthcare-associated pathogens can be transmitted either through direct or indirect contact between patients and healthcare workers ( $\mathrm{HCWs}$ ), and contamination through hands is the most common route of transmission among all. These HCAIs can be prevented by strictly following the established infection control guidelines [4-6], in which hand hygiene is considered to be the most significant practice for the prevention of nosocomial infections [7].
The practice of hand hygiene by HCWs, through the use of either soap/water or an alcohol-based hand sanitizer, is widely considered to be the most important and effective means of protecting and preventing transmission from the HCAIs. Though a very simple and easy technique, several studies have shown that compliance with hand hygiene among healthcare providers is as low as less than $40 \%$ [7-10]. In a questionnaire- and observational-based study, authors found a low overall rate of hand hygiene among 60 nursing students, and that their hand hygiene practices were significantly better when their mentor attempted hand hygiene practices [11]. In another study, Van De Mortel et al., reported that nursing students' hand hygiene knowledge and self-protection practices were significantly better than that of medical students [12]. Studies have been conducted in the Kingdom of Saudi Arabia (KSA) to monitor hand hygiene practices in certified healthcare providers $[13,14]$. However, only one significant study has been undertaken where medical students were also evaluated [15]. 
Among all HCWs, nurses form a larger group and play a central role in any healthcare setting. Since providing patients' care is one of their direct tasks, nurses should be properly trained, and their compliance with the hand hygiene guidelines is pivotal in protecting the patients and preventing the transmission of HCAIs $[16,17]$. According to the World Health Organization (WHO), the prevalence of nosocomial infections is as high as $19 \%$ in developing countries, posing a challenge to healthcare providers. For proper training, basic awareness about handwashing guidelines among the hospital personnel is required to reduce this burden of nosocomial infections. Hand washing by water and soap for 20-30 seconds could be life-saving especially for HCWs. The importance of hand hygiene and washing are brewing high importance due to the spreading of many contagious diseases, such as severe acute respiratory syndrome (SARS), MRSA, Middle East respiratory syndrome (MERS), and the recent COVID-19 pandemic as reported by WHO. Keeping the importance of handwashing in controlling the spread of nosocomial infections, the present study is performed to assess the general and hand hygiene practices among the medical and nursing students of the University of Hail, KSA.

\section{Procedure}

The present study is a quasi-experimental, cross-sectional, questionnaire-based study, conducted over three months among medical and nursing students of the University of Hail of KSA. A detailed questionnaire, consisting of thirty (30) questions, focusing on general and hand hygiene practices, was prepared and piloted before the final interview. The questions focused mainly on general and hand hygiene practices. A total of 100 medical $(n=50)$ and nursing $(n=50)$ students were included in the study. Out of these, 88 were males and 12 were females. The study was conducted after approval from the Ethics committee, college of medicine, University of Hail, KSA.

Before participation, the purpose of this study was explained to each student as per the ethical guidelines of the college. Students were requested to answer the questionnaires after assuring them of the fact that the results of this survey had no impact on their final grades in examinations. The participation of students was voluntary and the questionnaires were kept anonymous. However, the identifying data of students who opted not to respond to the questionnaire were recorded to exclude them from the assessment of compliance. The total number of responses was collected and data was processed and analyzed using SPSS (version 20.0) and Microsoft Excel software.

\section{RESULTS}

The present study is conducted on students from medical and nursing colleges. The majority of the respondents were male from either medical $(94 \%)$ or nursing $(82 \%)$ colleges, while the number of female respondents was only $6 \%$ and $18 \%$ respectively (Figure-1).

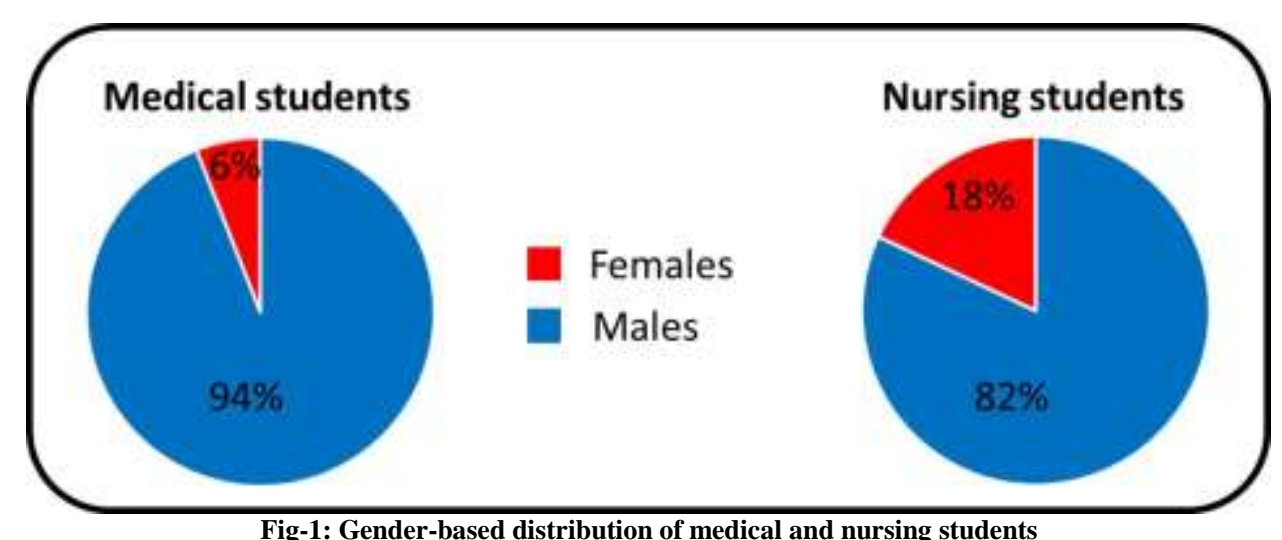

Fig-1: Gender-based distribution of medical and nursing students

Daily bathing and change of clothes practices were among all the medical students (100\%), while the corresponding number was $96 \%$ among nursing students. Fingernails cleaning practice was also among all the medical students (100\%), while $98 \%$ among nursing students. Overall, the majority of both medical and nursing students had good hygienic practices. There was no significant $(p>0.05)$ difference in the hygienic practices between medical and nursing students. The majority of both medical and nursing students had good hand washing practices. Using soap to wash hands before meal practice was higher among nursing students $(64 \%)$ than medical students $(42 \%)$ with significant $(\mathrm{p}=0.02)$ association (Table-1). 
Table-1: Comparison of hygienic practices between medical and nursing students

\begin{tabular}{|l|l|l|l|l|l|}
\hline \multirow{2}{*}{ Hygienic practices\# } & \multicolumn{2}{l}{$\begin{array}{l}\text { Medical } \\
\text { (n=50) }\end{array}$} & \multicolumn{2}{l}{$\begin{array}{l}\text { Nursing } \\
\text { (n=50) }\end{array}$} & \multirow{2}{*}{-value } \\
\cline { 2 - 5 } & No. & \% & No. & \% & \\
\hline Daily bathing and change of clothes & 50 & 100.0 & 48 & 96.0 & 0.15 \\
\hline Fingernails cleaning & 50 & 100.0 & 49 & 98.0 & 0.31 \\
\hline Fingernails trimming & 47 & 94.0 & 48 & 96.0 & 0.64 \\
\hline Use of hand tissue while coughing and sneezing & 47 & 94.0 & 47 & 94.0 & 1.00 \\
\hline Combing of hairs & 49 & 98.0 & 49 & 98.0 & 1.00 \\
\hline Cleaning of ears and eyes & 43 & 86.0 & 48 & 96.0 & 0.08 \\
\hline Nail-biting & 19 & 38.0 & 24 & 48.0 & 0.31 \\
\hline Washing socks daily & 29 & 58.0 & 35 & 70.0 & 0.21 \\
\hline Eating in clean place & 50 & 100.0 & 50 & 100.0 & - \\
\hline Washing of hands, legs, and face after playing & 50 & 100.0 & 50 & 100.0 & - \\
\hline Washing hands using water & 48 & 98.0 & 47 & 94.0 & 0.30 \\
\hline Washing hands using soap & 39 & 78.0 & 44 & 88.0 & 0.18 \\
\hline Washing hands before meal & 39 & 78.0 & 43 & 86.0 & 0.10 \\
\hline Using soap to wash hands before a meal & 21 & 42.0 & 32 & 64.0 & $\mathbf{0 . 0 2}$ \\
\hline Hand washing after going to the toilet & 47 & 94.0 & 43 & 86.0 & 0.18 \\
\hline Using soap to wash hands after going to the toilet & 35 & 70.0 & 42 & 84.0 & 0.09 \\
\hline
\end{tabular}

\#Multiple responses, ${ }^{I}$ Chi-square test, $*$ Significant

There was no significant difference $(\mathrm{p}>0.05)$ in the hygienic practices between male and female students except for the combing of hair practice. Nailbiting was higher among males (44.3\%) than females (33.3\%). However, washing socks daily was found to be higher among female (83.3\%) students compared to male $(61.4 \%)$ students. Hand washing practices were almost similar $(p>0.05)$ in both male and female students (Table-2).

Table-2: Comparison of hygienic practices between male and female students

\begin{tabular}{|l|l|l|l|l|l|}
\hline \multirow{2}{*}{ Hygienic practices\# } & \multicolumn{3}{|l|}{$\begin{array}{l}\text { Male } \\
(\mathbf{n = 8 8})\end{array}$} & \multicolumn{3}{l}{$\begin{array}{l}\text { Female } \\
(\mathbf{n = 1 2})\end{array}$} & \multirow{2}{*}{-value } \\
\cline { 2 - 6 } & $\mathbf{N o .}$ & $\mathbf{\%}$ & $\mathbf{\text { No. }}$ & $\mathbf{\%}$ & \\
\hline Daily bathing and change of clothes & 86 & 97.7 & 12 & 100.0 & 0.59 \\
\hline Fingernails cleaning & 87 & 98.9 & 12 & 100.0 & 0.71 \\
\hline Fingernails trimmed & 84 & 95.5 & 11 & 91.7 & 0.57 \\
\hline Use of hand tissue while coughing and sneezing & 84 & 95.5 & 10 & 83.3 & 0.09 \\
\hline Combing of hairs & 88 & 100.0 & 10 & 83.3 & $\mathbf{0 . 0 0 0 1}$ \\
\hline Cleaning of ears and eyes & 79 & 89.8 & 12 & 100.0 & 0.24 \\
\hline Nail-biting & 39 & 44.3 & 4 & 33.3 & 0.47 \\
\hline Washing socks daily & 54 & 61.4 & 10 & 83.3 & 0.13 \\
\hline Eating in clean place & 88 & 100.0 & 12 & 100.0 & - \\
\hline Washing of hands, legs, and face after playing & 88 & 100.0 & 12 & 100.0 & - \\
\hline Washing hands using water & 84 & 95.5 & 12 & 100.0 & 0.45 \\
\hline Washing hands using soap & 73 & 83.0 & 10 & 83.3 & 0.97 \\
\hline Washing hands before meal & 73 & 83.0 & 9 & 75.0 & 0.59 \\
\hline Using soap to wash hands before a meal & 45 & 51.1 & 8 & 66.7 & 0.31 \\
\hline Washing hands after going to the toilet & 80 & 90.9 & 10 & 83.3 & 0.41 \\
\hline Using soap to wash hands after going to the toilet & 66 & 75.0 & 11 & 91.7 & 0.19 \\
\hline
\end{tabular}

\#Multiple responses, ${ }^{1}$ Chi-square test, ${ }^{*}$ Significant

\section{DISCUSSION}

Healthcare-associated infection is a very important health issue globally, and hand hygiene is an effective method of infection control. Though the methods of hand hygiene are widely publicized and simple [10], several studies have found low awareness level regarding hand hygiene among medical students and certified healthcare providers [13, 14]. Students are bound to develop faulty hand hygiene practices if the curriculum was not enforced with hand hygiene concepts and skills. One such series is reported by Anwar et al (2009) from a leading medical training center in Pakistan where only $17 \%$ of interns and postgraduate medical students were aware of WHO recommendations on hand hygiene and only $4.7 \%$ reported observing correct hygiene before having direct contact with the patients [18]. It is for this valid reason 
that the Hygiene Liaison Group, UK strongly advocates teaching elementary hygiene practices at medical schools [19].

In the present study, the majority of the medical and nursing students were males $(88 \%)$ either in medical college $(94 \%)$ or in nursing college $(82 \%)$. On the contrary, Mahmood et al., reported that the majority of the healthcare workers were females (72.0\%) in their study [20]. This discrepancy could be attributed to the distribution of the questionnaire. In this study, the majority of both medical and nursing students had good hygienic practices. Similar findings were reported by Maheshwari et al., among staff nurses in a tertiary care hospital in Bhopal [21]. While washing practices were almost similar $(p>0.05)$, the results of this study showed no significant difference in the hygienic practices between male and female students except for the combing of hair $(\mathrm{p}>0.001)$. Kukanich et al., conducted a study in two outpatient healthcare clinics and reported that the frequency of hand hygiene was poor at baseline $(11 \%$ and $21 \%)$ but improved significantly after an intervention (36\% and 54\%) and through the follow-up period (32\% and 51\%) [22].

\section{CONCLUSION}

This study showed a higher percentage of general and handwashing hygienic practices among medical and nursing students at the University of Hail, KSA. However, multifaceted and dedicated efforts must be undertaken to rectify this practice from early on. As the world is facing dramatic changes due to the spreading of life-threatening infections such as Ebola, MERS, SARS, and recent pandemic COVID-19, protocols of hand hygiene and washing guidelines should take priority in hospitals and healthcare facilities among HCWs to control and prevent infections.

\section{ACKNOWLEDGMENTS}

We would like to extend our sincere thanks to the Dean, Vice Dean, and all faculty members of the University of Hail, as well as students with supervisors of the participating colleges (medicine and nursing) for helping us in the completion of this study.

\section{REFERENCES}

1. Jarvis, W. R. (1996). Selected aspects of the socioeconomic impact of nosocomial infections: morbidity, mortality, cost, and prevention. Infection Control \& Hospital Epidemiology, 17(8), 552-557.

2. Allegranzi, B., Nejad, S. B., Combescure, C., Graafmans, W., Attar, H., Donaldson, L., \& Pittet, D. (2011). Burden of endemic health-careassociated infection in developing countries: systematic review and meta-analysis. The Lancet, 377(9761), 228-241.

3. Holmes, A. H., Moore, L. S., Sundsfjord, A., Steinbakk, M., Regmi, S., Karkey, A., ... \& Piddock, L. J. (2016). Understanding the mechanisms and drivers of antimicrobial resistance. The Lancet, 387(10014), 176-187.

4. Haley, R. W., Culver, D. H., White, J. W., Morgan, W. M., Emori, T. G., Munn, V. P., \& Hooton, T. M. (1985). The efficacy oe infection surveillance and control programs in preventing nosocomial infections in us hospitals. American journal of epidemiology, 121(2), 182-205.

5. Mehta, Y., Gupta, A., Todi, S., Myatra, S. N., Samaddar, D. P., Patil, V., ... \& Ramasubban, S. (2014). Guidelines for prevention of hospital acquired infections. Indian journal of critical care medicine: peer-reviewed, official publication of Indian Society of Critical Care Medicine, 18(3), 149-163.

6. Rosenthal, V. D., Maki, D. G., \& Graves, N. (2008). The International Nosocomial Infection Control Consortium (INICC): goals and objectives, description of surveillance methods, and operational activities. American journal of infection control, 36(9), e1-e12.

7. World Health Organization. (2009). WHO Guidelines on Hand Hygiene in Health Care: a Summary. World Health Organization.

8. Al Kadi, A., \& Salati, S. A. (2012). Hand hygiene practices among medical students. Interdisciplinary perspectives on infectious diseases, 2012: 679129.

9. Kelcíkova, S., Skodova, Z., \& Straka, S. (2012). Effectiveness of hand hygiene education in a basic nursing school curricula. Public Health Nursing, 29(2), 152-159.

10. Mathur, P. (2011). Hand hygiene: back to the basics of infection control. The Indian journal of medical research, 134(5), 611-620.

11. Snow, M., White Jr, G. L., Alder, S. C., \& Stanford, J. B. (2006). Mentor's hand hygiene practices influence student's hand hygiene rates. American journal of infection control, 34(1), 18-24.

12. Van De Mortel, T. F., Kermode, S., Progano, T., \& Sansoni, J. (2012). A comparison of the hand hygiene knowledge, beliefs and practices of Italian nursing and medical students. Journal of advanced nursing, 68(3), 569-579.

13. Bukhari, S. Z., Hussain, W. M., Banjar, A., Almaimani, W. H., Karima, T. M., \& Fatani, M. I. (2011). Hand hygiene compliance rate among healthcare professionals. Saudi Med J, 32(5), 5159.

14. Qushmaq, I. A., Heels-Ansdell, D., Cook, D. J., Loeb, M. B., \& Meade, M. O. (2008). Hand hygiene in the intensive care unit: prospective observations of clinical practice. Polskie Archiwum Medycyny Wewnetrznej, 118(10), 543547.

15. Basurrah, M. M., \& Madani, T. A. (2006). Handwashing and gloving practice among health care workers in medical and surgical wards in a tertiary care centre in Riyadh, Saudi 
Arabia. Scandinavian journal of infectious diseases, 38(8), 620-624.

16. Buerhaus, P. I., Auerbach, D. I., \& Staiger, D. O. (2007). Recent trends in the registered nurse labor market in the US: Short-run swings on top of longterm trends. Nursing Economics, 25(2), 59-66.

17. AbuAlRub, R. F. (2007). Nursing shortage in Jordan: what is the solution?. Journal of professional Nursing, 23(2), 117-120.

18. Anwar, M. A., Rabbi, S., Masroor, M., Majeed, F., Andrades, M., \& Baqi, S. (2009). Self-reported practices of hand hygiene among the trainees of a teaching hospital in a resource limited country. JPMA. The Journal of the Pakistan Medical Association, 59(9), 631-634.

19. Handwashing Liaison Group. (1999). Hand washing: A modest measure-with big effects. BMJ, 318(7185): 686 .
20. Mahmood, S. E., Verma, R., \& Khan, M. B. (2015). Hand hygiene practices among nursing students: importance of improving current training programs. Int J Community Med Public Health, 2, 466-471.

21. Maheshwari, V. (2014). A study to assess knowledge and attitude regarding hand hygiene amongst residents and nursing staff in a tertiary health care setting of Bhopal City. Journal of clinical and diagnostic research: JCDR, 8(8), DC04- DC7.

22. KuKanich, K. S., Kaur, R., Freeman, L. C., \& Powell, D. A. (2013). Evaluation of a hand hygiene campaign in outpatient health care clinics. AJN The American Journal of Nursing, 113(3), 36-42. 